\title{
Formulation, optimization, qualitative and quantitative analysis of new dosage form of corticosteroid
}

\author{
Arif Nazir*, Mumtaz Masih and Munawar lqbal
}

\begin{abstract}
Background: The objective of the present research work is to develop the entirely new drug product formulation (Ophthalmic Suspension) which belongs to the therapeutic class of steroids drugs (Corticosteroid). There are different dosage forms of Triamcinolone acetonide to treat different systemic as well as topical diseases as per patient symptomatic conditions. Due to non-availability of this active drug (Triamcinolone acetonide) ophthalmic dosage form in the national and international market research work is carried out to enter in this dosage form.

Results: In the formulation design and development, different inactive like polysorbate $30 \mathrm{mg} / \mathrm{mL}, \mathrm{PEG}-12$ glyceryl dimyristate $70 \mathrm{mg} / \mathrm{mL}$, ethyl alcohol $10 \mu \mathrm{L} / \mathrm{mL}$, citric acid $1 \mathrm{mg} / \mathrm{mL}$, sodium citrate $3.5-4.0 \mathrm{mg} / \mathrm{mL}$, BKC $0.15 \mathrm{mg} / \mathrm{mL}$ and water for injection have been used at different stages in different proportions during the manufacturing procedure. Gradient HPLC, C18 column, 5 m, 100 A, 3.9 mm × 300 mm, detector UVNis @ 254 nm, column oven, autosampler, degasser, is used and this analytical testing method is validated to obtain the accurate results. The excipients play different roles including solvent, antioxidant, solubilizer, emulsifier, antibacterial, preservative, anticoagulant, antimicrobial agent, surfactant and buffers in the stability of active drug for its excellent therapeutic output results. Correlation coefficient factor is greater than 0.999 which indicates that the method has good linearity at proposed concentration against triamcinolone acetonide.

Conclusions: Excellent physical and chemical properties like physical appearance, pH, specific gravity, viscosity, re-suspendability, sedimentation volume is accomplished to meet the requirements of the eye treatment products. On the basis of experimental results achieved during validation process, it can be assumed that the current analysis method is more accurate, precise, specific, linear and consistency indicating in the range of 70 to $130 \%$ of the analyte concentration. From the physical, chemical behaviors and chemical assay of the newly developed drug formulation of corticosteroid (triamcinolone acetonide) it is concluded that it can be probably put for further clinical trial in different phases for human use.
\end{abstract}

Keywords: Triamcinolone acetonide, Formulation, Development, Validation, Chromatography, Corticosteroid

\section{Background}

The formulation development includes developing and manufacturing of desired products of active ingredients which are both stable and acceptable to the patient for required usage or need. Different formulations in

*Correspondence: anmalik77@gmail.com

Department of Chemistry, The University of Lahore, Lahore, Pakistan development stages of different dosage forms required excipients of different properties like particle size, $\mathrm{pH}$, solubility, diluent, preservative, binders, modifiers etc. Medicinal drug products are formulated to counter the disease, patient safety and confidence build up on the basis of consistency of quality attributes retained within the assigned specification of the drugs and drug products $[1,2]$. 
Ophthalmic products are mostly developed for children, adults and elderly patients and poorly accepted by children. To avoid the use of preservatives with a possible harmfulness to the cornea or mucous membranes of an eye, single dose or multi-dose preparation in a special multi-dose container that does not require its contents to be preserved, should be considered for children. Chemically steroids are the organic natural compounds which are linked with each other in a specific way of four cycloalkane rings [3].

Two major types of steroids are existing within the human body. First corticosteroids found in adrenal gland present on kidney, aldosterone, which is controlling sodium concentration in the body. Second cortisol, which is controlling the body, such as serving as part of the body's stress response system to decrease inflammation. Steroids are short form of corticosteroids, synthetic products look like cortisol, a hormone that adrenal glands produce naturally. Triamcinolone acetonide is a synthetic glucocorticoid and it is an agonist of the glucocorticoid receptor, which is about five times as strong as cortisol. It has very little mineralocorticoid properties [4].

Triamcinolone acetonide is used in a number of veterinary medicine as a component in external balms, creams or ointments and in external sprays for the control of itching of the skin in dogs and other animals. Triamcinolone acetonide is used in human medicines and available in the form of ointment, cream, lotion, aerosol (spray), inhaler, tablets and injections in different label claims for oral practice as well as for skin and in paste form for mouth use [5].

Triamcinolone acetonide is used topically to heal the crusting, scaling, inflammation, itching, redness, dryness of skin and for skin issues like psoriasis i.e., dermal problem in which red, scaly coverings appears on some areas of the body and eczema i.e., dry and itchy skin, sometimes develop red, scaly rashes. Triamcinolone acetonide is considered as 9-Fluoro- $11 \beta, 16 \alpha, 17,21$ tetrahydroxypregna-1,4-diene-3,20-dione cyclic 16,17-acetal with acetone. It has chemical formula $\mathrm{C}_{24} \mathrm{H}_{31}$ $\mathrm{FO}_{6}$ and molecular weight 434.51. Figure 1 shows structural formula of triamcinolone acetonide.

Corticosteroids are natural hormones which produced in adrenal cortex of humans and other mammals, in the same way analogues of these hormones. There are two types of these corticosteroids, one glucocorticoids and other mineralocorticoids, which are playing major role in a wide range of biological processes, together with stress, immune system and regulation of inflammation and metabolism response of the vertebrates. These corticosteroids bind with plasma proteins in variable ranges and are processed mostly in the liver and are then expelled by the kidneys [6].

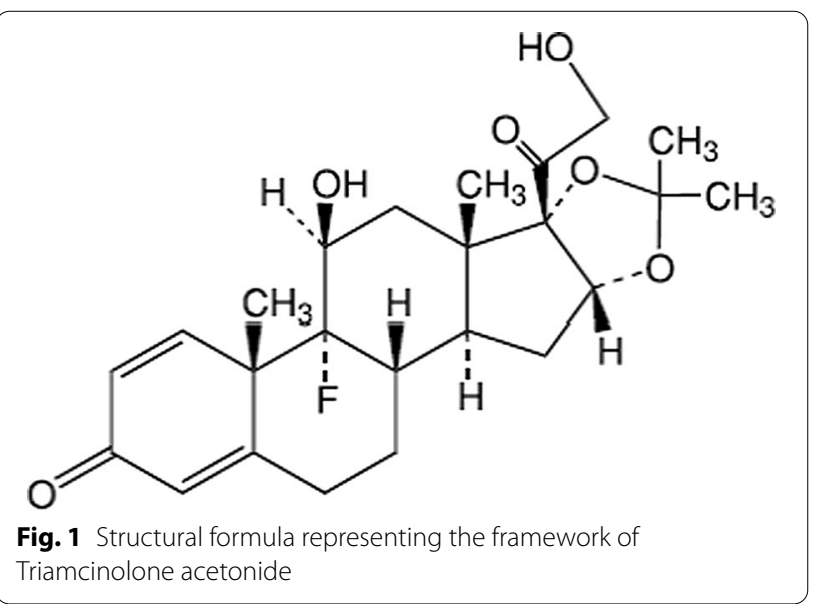

Different dosage forms of triamcinolone acetonide include nasal sprays, Inhaler, Oral, Topical and Injectable corticosteroids. Triamcinolone acetonide injection in suspension form, is a non-natural glucocorticoid, having anti-inflammatory properties. This preparation is appropriate for intramuscular (IM) and intra-articular (IV) use only. Triamcinolone acetonide injection is used to address a number of swelling and other conditions, like severe allergic reactions, skin issues, severe colitis, swelling of the joints or tendons, blood cell disorders, lung disorders, inflammatory eye disorders and some problems associated with by low adrenal gland hormones. Triamcinolone acetonide is an extra powerful derived from triamcinolone, and is almost eight times much better than triamcinolone itself [7].

The present formulation development related to a kind of ophthalmic suspension preparation, be specifically related to a kind of ophthalmic drug product that contains triamcinolone acetonide for treating ophthalmic diseases.

\section{Methods}

Triamcinolone acetonide (API) and working standard got from a well-known national pharmaceutical unit. Non-active pharmaceutical ingredient (Excipients) were purchased from the commercial market of Lahore. Each of the excipient used in the preparation or design and development plays a significant role for the integrity of formulation of this ophthalmic drug product. These excipients are non-toxic, pharmacologically inert, physically \& chemically stable, commercially available, acceptable to the regulatory point of view, have pleasing organoleptic properties and economical. Table 1 shows the role of non-active ingredients in formulation. 
Table 1 Role of non-active pharmaceutical ingredient in formulation

\begin{tabular}{lll}
\hline Sr. \# No & Excipients & Function/role \\
\hline 1 & Polysorbate (Tween 80) & Solvent, antioxidant \\
2 & PEG-12 glyceryl dimeristate & Solubilizer, emulsifier \\
3 & Ethyl alcohol & Solvent, antibacterial \\
4 & Citric acid anhydrous & Antioxidant, preservative \\
5 & Sodium citrate dihydrate & Anticoagulant, buffers \\
6 & Benzalkonium chloride & Preservative, antimicro- \\
7 & bial agent \& surfactant \\
& Water for injection (q.s) & Solvent \\
\hline
\end{tabular}

For the identification of active drug material FTIR@ ATR (Fig. 2) was performed and found comply with working standard given by the supplier.

\section{Drug product master formulation}

Master formulation of a drug product is a complete recipe of active drug and other ingredients in a specific quantity. It the master formulation of a drug product which makes it stable for long run use, any change in quantity and excipients makes it unstable. Drug product formulation is the process of mixing many chemical substances with the active drug to form a final medicinal product, which is called a medicine or drug product. Table 2 shows the drug product formulation.

\section{Manufacturing procedure of drug product}

Pour the "Polysorbate 80" (Tween 80), "PEG-12 Glyceryl dimeristate" in a gradated glass beaker of $1000 \mathrm{~mL}$ and later $300 \mathrm{~mL}$ water for injection in it, mixed well to homogenize it with the help of a magnetic stirrer for 5 min with continuously stirring at $1000 \mathrm{rpm}$. Raised the mixture temperature up to $121{ }^{\circ} \mathrm{C}$ with continuous

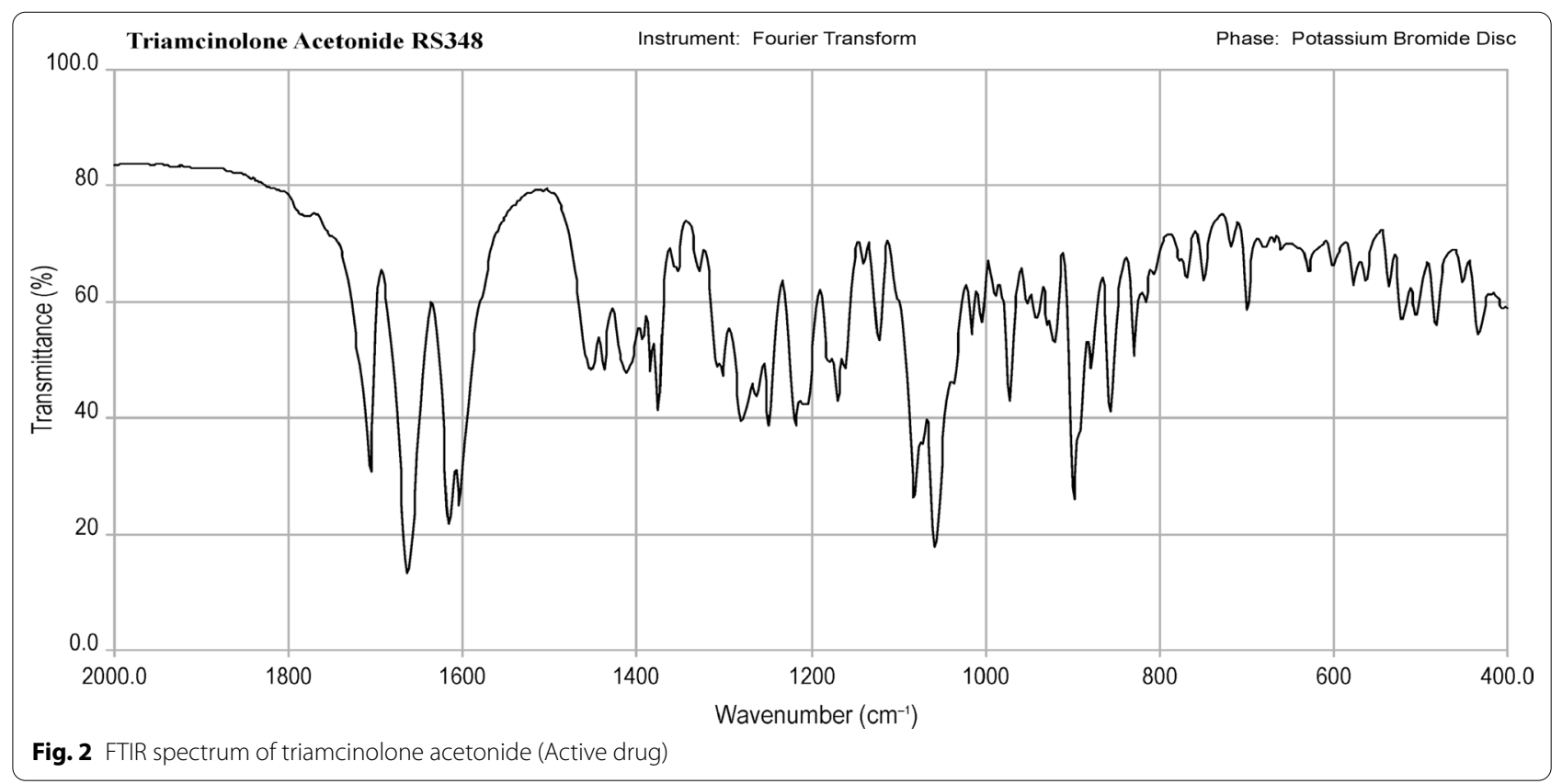

Table 2 Master formulation of triamcinolone acetonide eye drops suspension

\begin{tabular}{|c|c|c|c|c|}
\hline Sr. \# & Excipient & Qty/mL & Grade & Role/function \\
\hline 1 & Triamcinolone acetonide & $2.00 \mathrm{mg}$ & BP/USP & Active ingredient \\
\hline 2 & Polysorbate (Tween 80) & $30.0 \mathrm{mg}$ & USP/NF & Solvent, antioxidant \\
\hline 3 & PEG-12 glyceryl dimeristate & $70.0 \mathrm{mg}$ & USP/NF & Solubilizer, emulsifier \\
\hline 4 & Ethyl alcohol & $10 \mu \mathrm{L}$ & USP/NF & Solvent, antibacterial \\
\hline 5 & Citric acid anhydrous & $1.0 \mathrm{mg}$ & USP/NF & Antioxidant, preservative \\
\hline 6 & Sodium citrate dihydrate & $4.0 \mathrm{mg}$ & USP/NF & Anticoagulant, buffers \\
\hline 7 & Benzalkonium chloride & $0.15 \mathrm{mg}$ & USP/NF & $\begin{array}{l}\text { Preservative, antimicro- } \\
\text { bial agent \& surfactant }\end{array}$ \\
\hline 8 & Water for injection (q.s) & $1.0 \mathrm{~mL}$ & USP/BP & Solvent \\
\hline
\end{tabular}


stirring and heated for 15 min with continuously stirring at $1000 \mathrm{rpm}$. Cool down the mixture with continuously stirring up to 50 to $60^{\circ} \mathrm{C}$. Added "Triamcinolone acetonide" which is active pharmaceutical ingredient and mixed continuously at $1000 \mathrm{rpm}$ for $10 \mathrm{~min}$. Cool down the total mixture with continuously stirring to $25-30{ }^{\circ} \mathrm{C}$. Added up to $50 \%$ water for injection of the total volume of the product slowly slowly and mixed by continuously stirring for $5 \mathrm{~min}$ at $1000 \mathrm{rpm}$.

After checking the temperature $25-30{ }^{\circ} \mathrm{C}$ added the "Ethyl Alcohol" in the above mixture and continuously at $800 \mathrm{rpm}$ for $5 \mathrm{~min}$. Prepared the buffer solution separately by adding one by one and continuously mixed for $5 \mathrm{~min}$ at 800 revolutions per minute at each addition in almost $10 \%$ of the total volume by adding Citric acid \& Sodium citrate $2 \mathrm{H}_{2} \mathrm{O}$ and Benzalkonium chloride. Added filtered ( 0.2 micron) solution of separately prepared of Citric acid, Sodium citrate dihydrate and Benzalkonium chloride in $10 \%$ total volume of drug product in water for injection slowly. Mixed the above solution continuously for $10 \mathrm{~min}$ at $900 \mathrm{rpm}$ for achieving the light milky suspension. Make up the final volume with the help of water for injection and mixed for $10 \mathrm{~min}$ at $900 \mathrm{rpm}$. White to off white colored drug product has been prepared, put the sample for analysis for physical and chemical parameters.

Chromatographic separation and resolution between the different components also depend on length, diameter, pore size, particle size of HPLC column, nature of mobile phase, $\mathrm{pH}$ and flow rate of mobile solution/phase. High performance liquid chromatography is a noteworthy practice for separation by adsorption mechanism. When the solute components passing through stationary phase's porous material, the components interact with adsorption surface sites by competing with the eluent components for better adsorption sites.

After the manufacturing procedure, a product is obtained which contains the API (drug triamcinolone acetonide) and excipients in a specified amount which gives the stability to the product $[8,9]$. Table 3 indicates the physicochemical properties of eye drop suspension.

\section{HPLC method of analysis of triamcinolone acetonide eye drops suspension}

Analytical method describes the parameters to be carried out for analysis of pharmaceutical drug product triamcinolone acetonide eye drops (Suspension) [10, 11]. Mix 65\% HPLC water and 35\% Acetonitrile and filter through 0.45 micron, sonicate and degas. Mix acetonitrile and water HPLC grade in ratio 40:60 and allow to temper before use.

Weigh accurately approximately $25 \mathrm{mg}$ of working standard of Triamcinolone acetonide and shift in $25 \mathrm{~mL}$ vol. glass flask. Added $7 \mathrm{~mL}$ of analytical standard methanol and $3 \mathrm{~mL}$ acetonitrile, sonicate it in ultrasonic device for $10 \mathrm{~min}$. Add $10 \mathrm{~mL}$ of diluent and leave it in ultrasonic bath until it dissolves. The volume is then made up to $25 \mathrm{~mL}$. This solution contains $1 \mathrm{mg} / \mathrm{mL}$ of triamcinolone acetonide. Mix the sample (suspension) well with glass rod. Transferred a $1 \mathrm{~mL}$ aliquot part of Triamcinolone acetonide ophthalmic eye drop suspension, equivalent to $1 \mathrm{mg}$ of Triamcinolone acetonide active pharmaceutical ingredient in $10 \mathrm{ml}$ vol. glass flask. Added $7 \mathrm{ml}$ of diluent solvent, then shake with ultrasound for $5 \mathrm{~min}$. Then dilute with diluent solvent and mix. Centrifuge at $10,000 \mathrm{rpm}$ for $5 \mathrm{~min}$, separate supernatant liquid, filter supernatant through $0.45 \mu \mathrm{m}$ membrane filter. This solution contains a theoretical concentration of $100 \mu \mathrm{g} / \mathrm{mL}$ of Triamcinolone Acetonide. Transfer to chromatograph vials.

As per International Council for Harmonization guideline $(\mathrm{ICH})$ injected the reference standard solution triamcinolone acetonide six times under the described operating conditions. Record the chromatograms and verify that the following parameters are achieved: The coefficient of variation: NMT $2.0 \%$, Coleus factor: NMT

Table 3 Physical and chemical properties of the eye drop suspension

\begin{tabular}{ll}
\hline Parameters & Specifications \\
\hline Description & White to off white, free of solid particles \\
$\mathrm{pH}$ & 5.5 to 6.5 \\
Specific gravity & $1.000-1.002 \mathrm{~g} / \mathrm{mL}$ \\
Viscosity & $250-300 \mathrm{cps}$ at $20^{\circ} \mathrm{C} @$ needle 1 at $300 \mathrm{rpm}$ \\
Re-suspendability & After 20 turns or less it is homogenized \\
Sedimentation volume & The supernatant liquid is not more than $50.0 \%$ \\
Identification & The retention time of sample and standard should be same \\
Triamcinolone acetonide & \\
Assay & $90-110 \%$ \\
Triamcinolone acetonide & \\
\hline
\end{tabular}


2.0, The capacity factor: NLT 2.0 and relative Retention Times: $10-11 \mathrm{~min}$.

\section{Chemical assay procedure}

Injected $20 \mu \mathrm{l}$ of sample solution of triamcinolone acetonide suspension and standard solution of triamcinolone acetonide solution into the HPLC maintaining above chromatographic conditions, record the results in form of chromatograms and measure the responses of peaks.

The percentage of triamcinolone acetonide were calculated with reference to concentration of triamcinolone acetonide in the ophthalmic eye drops suspension using the following given formula. by stirring as in above preparation procedure to find a homogenous suspension. Take a quantity of sample suspension equivalent to $25 \mathrm{mg}$ of triamcinolone acetonide in $25 \mathrm{~mL}$ vol. glass flask, added $7 \mathrm{~mL}$ of analytical grade methanol, $3 \mathrm{~mL}$ of analytical grade acetonitrile, sonicate it in ultrasonic $10 \mathrm{~min}$. Added $10 \mathrm{~mL}$ of diluent and leave it in ultrasonic bath until it homogenizes. Warm it and dilute it with diluent to make up the volume. This solution contains $1.0 \mathrm{mg} / \mathrm{mL}$ of triamcinolone acetonide.

Now prepare the following strengths from the stock solution with diluent in $25 \mathrm{~mL}$ volumetric flask.

Weigh accurately $250 \mathrm{mg}$ of triamcinolone acetonide working standard into a volumetric flask of $100 \mathrm{~mL}$,

$$
\begin{aligned}
& \text { Chemical assay }=(\mathrm{rU} / \mathrm{rS}) \times(\mathrm{cS} / \mathrm{cU}) \times \mathrm{P} \\
& \text { Response of sample solution }(\mathrm{rU})=3104.746 \\
& \text { Response of Standard solution }(\mathrm{rS})=3211.063 \\
& \text { Concentration in the standard solution }(\mathrm{cS})=0.103 \mathrm{mg} / \mathrm{mL} \\
& \text { Concentration in the sample solution }(\mathrm{cU})=0.1 \mathrm{mg} / \mathrm{mL} \\
& \text { Purity of the working standard }(\mathrm{P})=99.94 \% \\
& \text { Chemical assay }=3104.746 / 3211.063 \times 0.103 / 0.1 \times 99.94=99.52 \%
\end{aligned}
$$

\section{Validation procedure for triamcinolone acetonide eye drops \\ Triamcinolone acetonide standard solution}

Weigh precisely $25 \mathrm{mg}$ of working standard of triamcinolone acetonide and transfer in $25 \mathrm{~mL}$ vol. flask. Added $7 \mathrm{~mL}$ of HPLC grade methanol, $3 \mathrm{~mL}$ HPLC grade acetonitrile, sonicate it in ultrasonic $10 \mathrm{~min}$. Now added $10 \mathrm{~mL}$ of diluent and leave it in ultrasonic bath until it dissolves. Temper it and dilute it with diluent to make up the volume. This solution contains $1.0 \mathrm{mg} / \mathrm{mL}$ of triamcinolone acetonide.

\section{Determination of linearity and range}

Transfer quantities of stock solution to a $25 \mathrm{~mL}$ volumetric flask respectively to prepare the required concentrations of triamcinolone acetonide as shown. Diluent used to make the volume and mix well.

\section{Determination of precision (Intraday and Inter-day assay)}

Determine the intra-day assay precision by analyzing samples repeatedly $(3 x)$ times in a day. Determine interday precision by analyzing the sample over 3 days and preferably by changing the analyst in same lab. On same HPLC instrument.

\section{Determination of accuracy}

Transfer $2 \mathrm{~g}$ triamcinolone acetonide, $30 \mathrm{~g}$ polysorbate (Tween 80), 70 g PEG-12, $10 \mathrm{~mL}$ ethyl alcohol, 1 g citric acid, 4 g sodium citrate dihydrate, $0.150 \mathrm{~g}$ benzalkonium chloride and water for injection (q.s) $1 \mathrm{~L}$, mixing added $28 \mathrm{~mL}$ of analytical grade methanol and $12 \mathrm{~mL}$ of analytical grade acetonitrile, sonicate it in ultrasonic for $10 \mathrm{~min}$. Added $40 \mathrm{~mL}$ of diluent to dissolve and complete to volume with same diluent. Take $10 \mathrm{~mL}$ from stock solution "A" in $25 \mathrm{~mL}$ vol. flask, make the capacity up to spot with diluent solution. Take $10 \mathrm{~mL}$ from stock solution " $\mathrm{A}$ " in $50 \mathrm{~mL}$ vol. flask and make the capacity up to mark with diluent solution. Take $10 \mathrm{~mL}$ from stock solution 'A' in $100 \mathrm{~mL}$ vol. glass and make the capacity up to mark with diluent solution. Now mix above stock solutions to get $1000 \mu \mathrm{g} / \mathrm{mL}, 500 \mu \mathrm{g} / \mathrm{mL}$ and $250 \mu \mathrm{g} / \mathrm{mL}$ of triamcinolone acetonide respectively as shown.

\section{Placebo}

Transfer 30 g Polysorbate (Tween 80), 70 g PEG-12, $10 \mathrm{~mL}$ Ethyl Alcohol, $1 \mathrm{~g}$ Citric Acid, $4 \mathrm{~g}$ Sodium Citrate Dihydrate, $0.150 \mathrm{~g}$ Benzalkonium Chloride and Water for Injection (q.s) $1 \mathrm{~L}$, mixing by stirring as in above "Preparation of Drug Product" to find a homogenous suspension. Proceeded as "Sample Solution Preparation of Triamcinolone Acetonide Suspension" and then injected as a sample.

\section{Results}

The results are mentioned in Tables 4, 5, 6, 7, 8 and 9.

Six repeated injections of standard solution $(100 \%$ concentration) of triamcinolone acetonide were injected into the HPLC chromatograph and the results are shown. The \%RSD for 6 injections of standard solution for triamcinolone acetonide was found to 
Table 4 Results of different analytical method validation parameters

\begin{tabular}{|c|c|}
\hline Study & Results \\
\hline Specificity & $\begin{array}{l}\text { The method was found selective and specific for triamcinolone acetonide eye drops (suspension), since there is no } \\
\text { any interference from placebo in the retention time of triamcinolone acetonide active pharmaceutical drug }\end{array}$ \\
\hline Linearity & A linear relation was found for this HPLC method. The correlation co-efficient was found to be 1.00 \\
\hline Precision & The results were found within the acceptance value of relative standard deviation (\% RSD $\leq 1.0 \%$.) \\
\hline System precision & $\begin{array}{l}\% \text { RSD of triamcinolone acetonide peak areas for six replicate injections of standard solutions are } 0.395 \% \text {, which is } \\
\text { less than } \leq 1.0 \%\end{array}$ \\
\hline Intraday precision & Cumulative intraday precision of triamcinolone acetonide is $101.48 \%$ with cumulative RSD $0.22 \%$ respectively \\
\hline Inter-day precision & Cumulative inter-day precision of triamcinolone acetonide $101.71 \%$ with cumulative RSD $0.31 \%$ respectively \\
\hline Accuracy \& Recovery & $\begin{array}{l}\text { The amount of triamcinolone acetonide recovered in recovery I for eye drop were } 101.68 \% \text { with RSD } 1.17 \% \text { respec- } \\
\text { tively }\end{array}$ \\
\hline Range & Range was found to cover $70-130 \%$ of the sample concentration \\
\hline Stability of analytical test solution & $\begin{array}{l}\text { The analytical solution is stable for } 24 \mathrm{~h} \text { when stored at room temperature assay value for } 100.37 \% \text { with RSD } 0.87 \% \\
\text { respectively }\end{array}$ \\
\hline $\operatorname{LOD}(\mu \mathrm{g} / \mathrm{mL})$ & Triamcinolone acetonide (active drug) LOD: $0.096(\mu \mathrm{g} / \mathrm{mL})$ \\
\hline $\mathrm{LOQ}(\mu \mathrm{g} / \mathrm{mL})$ & Triamcinolone acetonide (active drug) LOQ: 0.31 ( $\mu \mathrm{g} / \mathrm{mL}$ ) \\
\hline
\end{tabular}

Table 5 Chromatographic data of working standards and drug product

\begin{tabular}{lcccc}
\hline Sample name & Peak area & RT(Min) & Height & Area\% \\
\hline Blank 1 & - & - & - & - \\
Blank 2 & & & & \\
Standard 01 & 3216.93 & 10.727 & 144.40 & 100 \\
Standard 02 & 3209.86 & 10.723 & 142.14 & 100 \\
Standard 03 & 3206.40 & 10.719 & 142.68 & 100 \\
Standard 04 & 3208.02 & 10.744 & 145.01 & 100 \\
Standard 05 & 3207.81 & 10.748 & 142.36 & 100 \\
Standard 06 & 3180.10 & 10.530 & 147.96 & 100 \\
Sample 01-1 & 3103.19 & 10.731 & 140.10 & 100 \\
Sample 01-2 & 3108.89 & 10.738 & 139.96 & 100 \\
Sample 02-1 & 3259.57 & 10.743 & 151.30 & 100 \\
Sample 02-2 & 3266.77 & 10.717 & 152.17 & 100 \\
Sample 03-1 & 3115.08 & 10.731 & 140.47 & 100 \\
Sample 03-2 & 3126.83 & 10.734 & 140.01 & 100 \\
Sample 04-1 & 3081.46 & 10.695 & 139.96 & 100 \\
Sample 04-2 & 3078.29 & 10.625 & 142.65 & 100 \\
Sample 05-1 & 3102.29 & 10.590 & 143.98 & 100 \\
Sample 05-2 & 3107.20 & 10.563 & 144.48 & 100 \\
Sample 06-1 & 3081.74 & 10.553 & 143.47 & 100 \\
Sample 06-2 & 3090.28 & 10.550 & 143.89 & 100 \\
\hline
\end{tabular}

be $0.395 \%$, indicating the results are within acceptable precision. Figure 3 represents chromatogram for standard injection.

Here RSD\% is less than $1.0 \%$ for triamcinolone acetonide against 6 replicated injections as indicated above, so it was considered satisfactory for the evaluation of other performance parameters.
Table 6 System suitability data for T. acetonide eye drops suspension

\begin{tabular}{ll}
\hline Repeated injections & Peak areas \\
\hline 1 & 3216.93 \\
2 & 3209.86 \\
3 & 3206.40 \\
4 & 3208.02 \\
5 & 3207.81 \\
6 & 3180.10 \\
Mean & 3204.85 \\
SD & 12.686 \\
\%RSD & 0.395 \\
\hline
\end{tabular}

\section{Determination of range and linearity}

The linearity of triamcinolone acetonide (Fig. 4) was determined in the specified range. The results are presented graphically. The results indicate that the response for the triamcinolone acetonide peak was linear over the specified range $70-130 \%$ of the sample concentration.

\section{Determination of precision Intraday \& inter-day for Triamcinolone acetonide}

The precision level of the triamcinolone acetonide eye drops suspension sample was found by replicate analysis. Cumulative intraday and inter-day variability were below $2 \%$ for triamcinolone acetonide as shown below. The intraday and inter-day accuracy of the triamcinolone acetonide was $101.02 \%$ and $101.08 \%$ with cumulative RSD $0.06 \%$ and $0.082 \%$ respectively. The results below show that the given method was accurate and precise. 
Table 7 Triamcinolone acetonide range \& linearity

\begin{tabular}{lll}
\hline $\begin{array}{l}\text { Concentration (Triamcinolone acetonide) }(\boldsymbol{\mu g} / \\
\mathbf{m L})\end{array}$ & Range (\%) & Area values (Triamcinolone acetonide) \\
$\mathbf{7 0 0} \boldsymbol{\mu g} / \mathbf{m L}$ T. acetonide & $\mathbf{7 0}$ & $\mathbf{2 1 7 1}$ \\
\hline $900 \mu \mathrm{g} / \mathrm{mL}$ T. acetonide & 90 & 2794 \\
$1000 \mu \mathrm{g} / \mathrm{mL}$ T. acetonide & 100 & 3103 \\
$1100 \mu \mathrm{g} / \mathrm{mL}$ T. acetonide & 110 & 3415 \\
$1300 \mu \mathrm{g} / \mathrm{mL}$ T. acetonide & 130 & 4035 \\
Slope & & 31.065 \\
Intercept & & -2.900 \\
Correlation coefficient & & 1.000 \\
Regression standard deviation root mean square & & 0.96 \\
Limit of detection $(\mu \mathrm{g} / \mathrm{mL})$ & 0.09 \\
Limit of quantification $(\mu \mathrm{g} / \mathrm{mL})$ & 0.31
\end{tabular}

\section{Accuracy and recovery}

Transfer a $1 \mathrm{~mL}$ aliquot part of triamcinolone acetonide ophthalmic eye drop suspension, equivalent to $1 \mathrm{mg}$ of triamcinolone acetonide active pharmaceutical ingredient in a $10 \mathrm{~mL}$ vol. glass flask. Added $7 \mathrm{~mL}$ of diluent, and shake with ultrasound up to $5 \mathrm{~min}$.

Temper and dilute with diluent and then mix. Centrifuge at 10,000 rpm for $5 \mathrm{~min}$, separate supernatant liquid, filter supernatant through $0.45 \mu \mathrm{m}$ membrane filter. This solution contains a theoretical concentration of $1000 \mu \mathrm{g} /$ $\mathrm{mL}$ of triamcinolone acetonide. The mobile phase was used to dilute the stock solution to achieve $70-130 \%$ sample concentration. The amounts recovered were calculated by using following formula.

$\%$ Recovery $=\left(\mathrm{C}_{\text {found }} / \mathrm{C}_{\text {added }} \times 100\right)$.

The results indicate that the procedure has acceptable recovery level.

The mean recovery and relative standard deviation for standard solutions with excipients was found to be $101.6 \%$ with RSD $0.02 \%$ for Recovery I respectively. The excipients or inactive chemicals used in the drug product did not interfere in the analysis with active drug. The amount of T. acetonide recovered in Recovery II are $100.76 \%$ with RSD 0.53 respectively. The results indicate that the method has acceptable level of recovery.

\section{Range}

From the linearity, precision, accuracy as well as working range of the analytical method, was concluded to be $70-130 \%$ of the sample concentration.

\section{Stability of standard solution}

The sample solutions were prepared, analyzed initially at various time intervals and then stored at room temperature. On the basis of result, it is specified that the sample solution is stable for $24 \mathrm{~h}$ at room temperature.

\section{Sensitivity (LOD \&LOQ)}

According to the ICH guidelines the LOD and LOQ can be determined by using the formula given: LOD was assessed as $3 \times \mathrm{s} / \mathrm{k}$ while LOQ was assessed as $10 \times \mathrm{s} / \mathrm{k}$, here $\mathrm{k}$ represents, slope of the calibration curve while $\mathrm{s}$ represents the root mean square error regression standard deviation. Triamcinolone acetonide LOD value $0.096 \mu \mathrm{g} / \mathrm{mL}$ and LOQ value $0.31 \mu \mathrm{g} / \mathrm{mL}$.

\section{Discussion}

The present drug product formulation development is an ophthalmic dosage form (Eye drops suspension) which belongs to the class of steroid. The active drug triamcinolone acetonide decreases chronic inflammation and other severe allergic reaction. Other dosage forms of the triamcinolone acetonide are present in the form of tablets, capsules, liquid injections, dry powder injections, creams/ointments, lotions, oral pastes, inhalers and nasal sprays in the market by manufacturer. The present ophthalmic formulation development was carried out to develop the eye drops suspension because of non-availability of this dosage form in the market on commercial scale on national as well as international level $[12,13]$.

Nowadays the suspension drug products formulations are also emerging in the form of eye drops of different drugs like the antibiotic and pain killers etc. In the development of triamcinolone acetonide eye drops suspension different inactive have been used as per drug product design and development which are inert itself and play different physiochemical roles in product formulation development, drug product characterization and stability for long term uses. The present developed formulation found stable as per different specifications [14]. 


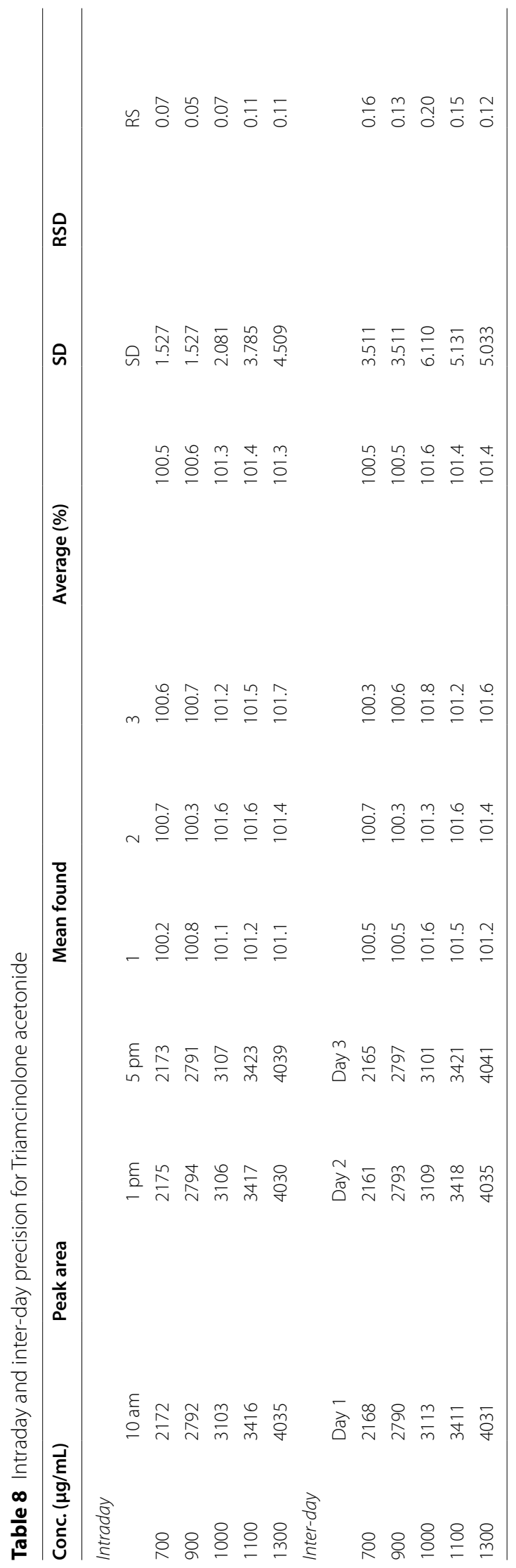


Table 9 Data showing the results for recovery I and II

\begin{tabular}{llll}
\hline Triamcinolone acetonide & & & \\
& Mean area & Recovery (\%) & $\begin{array}{l}\text { RSD } \\
\text { (\%) }\end{array}$ \\
\hline Recovery / Added $(\mu \mathrm{g} / \mathrm{mL})$ & & & \\
$700 \mu \mathrm{g} / \mathrm{mL}$ T. acetonide (70\%) & 2174.21 & 101.6 & 0.02 \\
$1000 \mu \mathrm{g} / \mathrm{mL}$ T. acetonide (100\%) & 3103.89 & 100 & 0.05 \\
$1300 \mu \mathrm{g} / \mathrm{mL}$ T. acetonide (130\%) & 4038.6 & 99.80 & 0.14 \\
Placebo & No Peak & - & - \\
Recovery II Added $(\mu \mathrm{g} / \mathrm{mL})$ & & & \\
$800 \mu \mathrm{g} / \mathrm{mL}$ T. acetonide (80\%) & 2660.87 & 100.76 & 0.53 \\
$1000 \mu \mathrm{g} / \mathrm{mL}$ T. acetonide (100\%) & 3326.09 & 100 & 0.08 \\
$1200 \mu \mathrm{g} / \mathrm{mL}$ T. acetonide (120\%) & 3991.30 & 99.88 & 0.08 \\
\hline
\end{tabular}

\section{Development of drug product}

Each drug and drug product starts its finding and complete development in labs. Pharmaceutical organizations devote millions of rupees in such new investigations and development which comprises technical study and advancement of drugs for novelty. Capital investment may come from numerous areas as well as government grants, revenues, investors and donors etc. When the drug finding has been completed, its initial demand that it is essential to go for individually preclinical and clinical investigations with supportive results tangled to its assessment procedure. Preclinical investigation is a rudimentary initial stage that comprises checking of the drug on different animals and this initial checking is for protection measures [15-17].

This experimental (clinical) investigation is one of the utmost important step ladders in a drug's growth or development. If any drug passes such initial stage experimental tests or trials, then it is shifted next to experimental (clinical) testing which includes human beings' trials on volunteers. During new drug formulation advancement stages, the option of usage of new excipients and other materials depends on physiochemical behavior and active drug stability, like $\mathrm{pH}$ for an optical preparation is 7.4, comparable to eye tear liquid. However, most of active drug's products in finished form are unstable at this $\mathrm{pH}$, so it is too important to understand the active drug properties. Therefore, if buffers chemicals are involved, must enable $\mathrm{pH}$ as close as possible to the functional $\mathrm{pH}$, and not creating any chemical instability.

When the preparation profile is recognized, the initial stage in product development is launching its physical and chemical characteristics like as physical appearance, thickness, viscosity, osmolarity and $\mathrm{pH}$ etc.

\section{Mode of action of new development}

The present drug product is ophthalmic dosage (Eye drops suspension) form which belongs to the class of

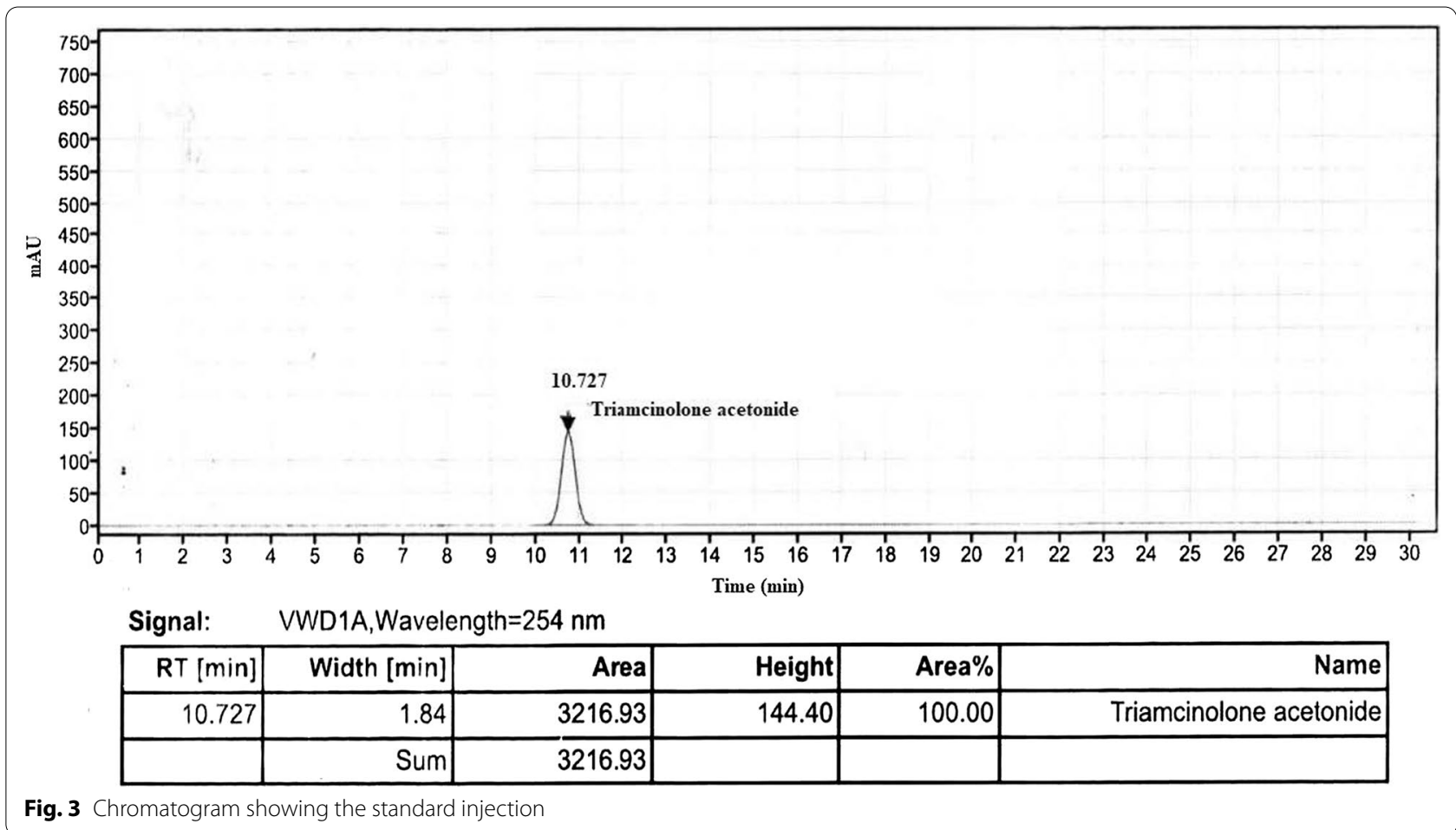




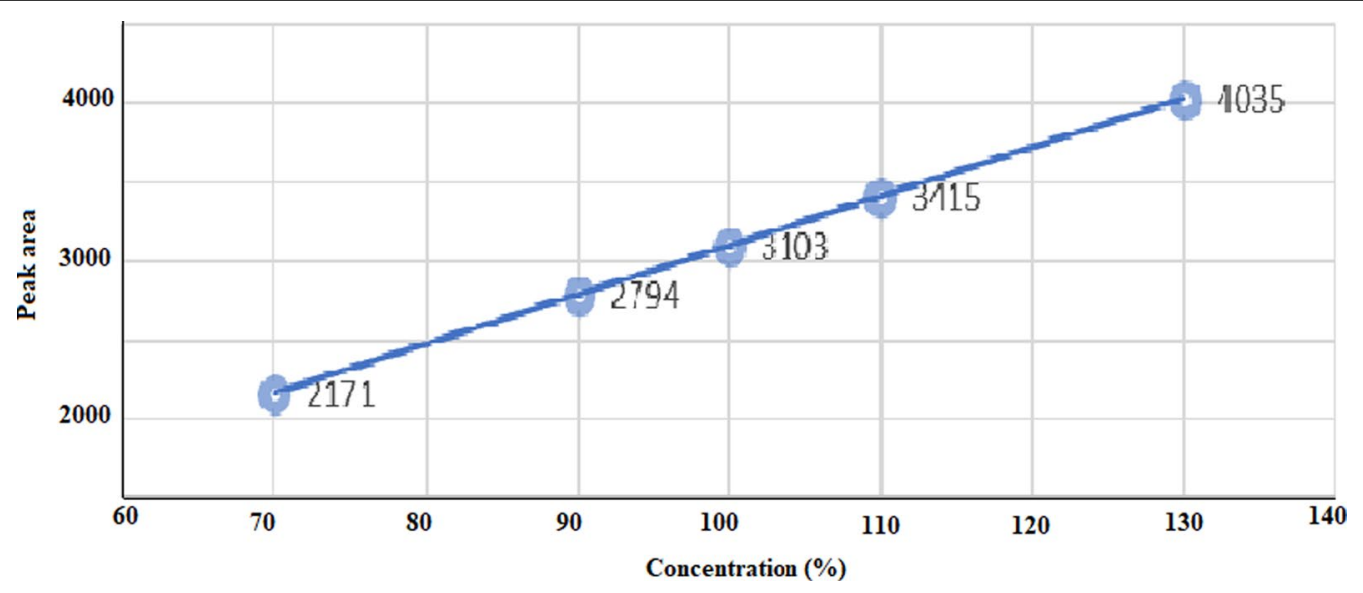

Fig. 4 Graph showing linearity for Triamcinolone acetonide

steroid. Triamcinolone acetonide is the acetonide salt form of triamcinolone drug, a synthetic glucocorticosteroid with immunosuppressive and anti-inflammatory properties. Triamcinolone acetonide binds to a specific cytosolic glucocorticoid receptor and then interacts with glucocorticoid receptor response element on DNA and modifies gene expression. This results in an initiation of the synthesis of some anti-inflammatory proteins while inhibiting the synthesis of certain inflammatory mediators. Subsequently, a general decrease in chronic inflammation and autoimmune reactions are accomplished.

Other dosage forms of the triamcinolone acetonide are in the form of creams, ointments, lotions, oral pastes, inhalers, tablets, capsules, liquid injections, dry powder injections and nasal sprays in the market manufactured by different national and multinational pharmaceutical companies.

In the manufacturing procedure very economical and quite save methodology have been adopted to retain the efficacy of the parent drug (API). All the materials which have been used in the development are of pharmaceutical grade and tested properly before the development of the drug product to have the control and check on the properties of the drug product. Each excipient has its own specific properties to control the physicochemical properties to attain the particular specs in the drug product, similarly in the analytical work of the drug product all the chemicals which have been used are of high quality of world fame manufacturer with latest analytical equipment.

\section{Conclusions}

An ophthalmic product formulation may be in the form of a solution, suspension, an emulsion or ointment/ cream. A representative eye attention or care drug product formulation must be sterilized, isosmotic, with some suitable $\mathrm{pH}$ property, comprises antimicrobial representatives with excellent container closure packaging, multi-dose or single dose administration system.

HPLC analysis method using reverse phase chromatographic technique with UV/Vis detector was established and validated for the determination of triamcinolone acetonide in a newly developed drug product at lab. scale for its intended use at commercial scale and consistency study analysis. The HPLC method specified in the procedure for qualitative and quantitative determination triamcinolone acetonide was confirmed for accuracy, precision, specificity, LOD, LOQ, linearity, stability of standard solution. This established HPLC method is rapid, economical and reliable for intended use and for the determination of a drug component in new developed and formulated ophthalmic dosage form triamcinolone acetonide eye drops suspension. The method designed specifically hasn't any interference with excipients.

The significant feature of the analytical analysis method validation is that it was designed and assured gradient procedure which is easy to run on any kind or brand of HPLC. It is time saving, environmentally friendly. The current designed analysis procedure has reliably accurate and precise. It is concluded that this analytical method is valid for the identification and chemical assay determination of active ingredient (triamcinolone acetonide) in the newly developed ophthalmic dosage form.

\footnotetext{
Abbreviations

USP: United States Pharmacopeia; NF: National Formulary; CPS: Counts per seconds; LOD: Limit of Detection; LOQ: Limit of Quantification; RSD: Relative Standard Deviation; BP: British Pharmacopeia; Ph. Eur: European Pharmacopoeia; HPLC: High performance liquid chromatography; ICH: International Council for Harmonization; NMT: Not more than; NLT: Not Less than; BKC: Benzalkonium chloride; PEG: Poly Ethylene Glycol; IM: Intramuscular; IV:
} 
Intravenous; q.s: Quantum satis; FTIR@ATR: Fourier Transform Infra-Red with Attenuated Total Reflectance; Qty: Quantity; COPD: Chronic obstructive pulmonary disease; UVNis: Ultraviolet-visible (UV-Vis) spectrophotometry; TAA :Triamcinolone acetonide; RH: Relative humidity; API: Active pharmaceutical ingredient.

\section{Acknowledgements}

We are thankful for all those who have supported us during this project.

\section{Authors' contributions}

AN contributed to the conception, design, interpretation of data and preparation of first draft. MM has performed all the experiments and was responsible for data acquisition. MI has proof read the draft of the work for the project and also helped in interpretation of data. All authors read and approved the final manuscript.

\section{Funding}

There is no funding source for this project.

\section{Declarations}

Ethics approval and consent to participate Not Applicable.

\section{Consent for publication}

Not Applicable.

\section{Availability of data and materials}

The datasets used and/or analyzed during the current study are available from the corresponding author on reasonable request.

\section{Competing interests}

The authors declare that they have no competing interests.

Received: 1 July 2021 Accepted: 7 October 2021

Published online: 16 October 2021

\section{References}

1. Nazir A, lqbal J, lqbal M, Abbas M, Nisar N (2020) Method validation for bifenthrin emulsifiable concentrate and uncertainty calculation using gas chromatographic approach. Fut J Pharmaceut Sci 6(1):5

2. Iqbal DN, Ashraf A, lqbal M, Nazir A (2020) Analytical method development and validation of hydrocortisone and clotrimazole in topical dosage form using RP-HPLC. Fut J Pharmaceut Sci 6(1):49

3. Muankaew C, Jansook P, Sigurđsson HH, Loftsson T (2016) Cyclodextrinbased telmisartan ophthalmic suspension: formulation development for water-insoluble drugs. Int J Pharmaceut 507(1):21-31
4. Maharjan P, Cho KH, Maharjan A, Shin MC, Moon C, Min KA (2019) Pharmaceutical challenges and perspectives in developing ophthalmic drug formulations. J Pharma Inves 49(2):215-228

5. Coffey MJ, Decory HH, Lane SS (2013) Development of a non-settling gel formulation of $0.5 \%$ loteprednol etabonate for anti-inflammatory use as an ophthalmic drop. Clin Ophth 7:299-312

6. Zacharias LC, Lin T, Migon R, Ghosn C, Orilla W, Feldmann B, Ruiz G, Li Y, Burke J, Kuppermann BD (2013) Assessment of the differences in pharmacokinetics and pharmacodynamics between four distinct formulations of triamcinolone acetonide. Retina 33(3):522-531

7. Padula C, Telò I, Di lanni A, Pescina S, Nicoli S, Santi P (2018) Microemulsion containing triamcinolone acetonide for buccal administration. Eur J Pharmaceut Sci 115:233-239

8. Li J, Cheng T, Tian Q, Cheng Y, Zhao L, Zhang X, Qu Y (2019) A more efficient ocular delivery system of triamcinolone acetonide as eye drop to the posterior segment of the eye. Drug Deliv 26(1):188-198

9. Paik J, Duggan ST, Keam SJ (2019) Triamcinolone acetonide extendedrelease: a review in osteoarthritis pain of the knee. Drugs 79(4):455-462

10. Rozet E, Ceccato A, Hubert C, Ziemons E, Oprean R, Rudaz S, Boulanger B, Hubert P (2007) Analysis of recent pharmaceutical regulatory documents on analytical method validation. J Chrom 1158(1):111-125

11. Szepesi G, Gazdag M, Mihályfi K (1991) Selection of high-performance liquid chromatographic methods in pharmaceutical analysis: III. Method validation J Chrom A 464:265-278

12. Carr GP, Wahlich JC (1990) A practical approach to method validation in pharmaceutical analysis. J Pharma Biomed Anal 8(8):613-618

13. Pashankov PP, Kostova LL (1987) Reversed-phase high-performance liquid chromatography of metronidazole benzoate in suspension dosage form. J Chrom A 394(2):382-387

14. Cavina G, Alimenti R, Gallinella B, Valvo L (1992) The identification of related substances in triamcinolone acetonide by means of highperformance liquid chromatography with diode array detector and mass spectrometry. J Pharma Biomed Anal 10(9):685-692

15. Hájková R, Solich P, Dvořák J, Šicha J, (2003) Simultaneous determination of methylparaben, propylparaben, hydrocortisone acetate and its degradation products in a topical cream by RP-HPLC. J Pharma Biomed Anal 32(4):921-927

16. Matysová L, Hájková R, Šícha J, Solich P (2003) Determination of methylparaben, propylparaben, triamcinolone acetonide and its degradation product in a topical cream by RP-HPLC. Anal Bioanal Chem 376(4):440-443

17. Sudsakorn S, Kaplan L, Williams DA (2006) Simultaneous determination of triamcinolone acetonide and oxymetazoline hydrochloride in nasal spray formulations by HPLC. J Pharma Biomed Anal 40(5):1273-1280

\section{Publisher's Note}

Springer Nature remains neutral with regard to jurisdictional claims in published maps and institutional affiliations.

\section{Submit your manuscript to a SpringerOpen ${ }^{\circ}$ journal and benefit from:}

- Convenient online submission

- Rigorous peer review

- Open access: articles freely available online

- High visibility within the field

- Retaining the copyright to your article

Submit your next manuscript at $\boldsymbol{\nabla}$ springeropen.com 